\title{
Identifying the key purchase factors for organic food among Chinese consumers
}

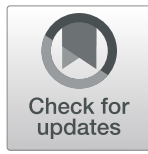

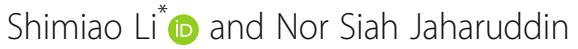

\author{
* Correspondence: lishimiao@yahoo. \\ com \\ Department of Management and \\ Marketing, School of Business and \\ Economics, Putra University, UPM, \\ Serdang, 43400 Seri Kembangan, \\ Selangor Darul Ehsan, Malaysia
}

\begin{abstract}
The current study primarily aims to identify the critical purchase factors that affect Chinese consumer purchase intention and purchase decision with regard to organic food consumption, in accordance with a modified theory of planned behavior and the alphabet theory. Specifically, this study builds a conceptual research framework by which to delve into the relationships between purchase factors and purchase intention, and elucidate the mediating roles of purchase factors in the relationships between purchase intention and purchase decision. Moreover, by leveraging a modified theory of planned behavior and the alphabet theory, the current study also determines the critical roles of subjective norms and reveals the information and knowledge that impact consumer attitude toward the purchase of organic food. The current study leverages the purposive sampling method and captures 310 records within Beijing, China. The results indicate that purchase attitude correlates positively with subjective norms and knowledge, while purchase intention correlates positively with purchase attitude, perceived behavior control, and food therapy culture. Furthermore, purchase intention can significantly mediate relationships between each of purchase attitude, perceived behavior control, food therapy culture, and purchase decision. Finally, we discuss the theoretical and practical significance of the framework, and propose subsequent research directions regarding organic food purchase behavior.

Keywords: Purchase behavior, Subjective norms, Knowledge, Purchase attitude, Perceived behavioral control, Food therapy culture, Organic food, China
\end{abstract}

\section{Introduction}

Within the global food market, sales of organic food have seen dramatic overall growth: In 2016, for example, worldwide sales of organic food grew by approximately 10\%, to USD89.7 billion. North America and Europe, two representative organic food markets, have continuously contributed to worldwide sales in organic food, as these two continents account for approximately $90 \%$ of worldwide sales (Sahota 2018). Data suggest that the organic food sector has also expanded rapidly in Asian countries (e.g., Bangladesh, China, India, Iran, Japan, South Korea, and Philippines) (FiBL and IFOAM-Organics International 2019).

In recent years, the organic food market has enjoyed a tremendous and noteworthy boost in Chinese mainland: In 2017, China's overall organic packaged food and

(c) The Author(s). 2020 Open Access This article is licensed under a Creative Commons Attribution 4.0 International License, which permits use, sharing, adaptation, distribution and reproduction in any medium or format, as long as you give appropriate credit to the original author(s) and the source, provide a link to the Creative Commons licence, and indicate if changes were made. The images or other third party material in this article are included in the article's Creative Commons licence, unless indicated otherwise in a credit line to the material. If material is not included in the article's Creative Commons licence and your intended use is not permitted by statutory regulation or exceeds the permitted use, you will need to obtain permission directly from the copyright holder. To view a copy of this licence, visit http://creativecommons.org/licenses/by/4.0/. 
beverages market brought in nearly USD2.84 billion in sales, and organic standard milk dominated overall value of sales, accounting for over $71 \%$ of all market value (FiBL and IFOAM - Organics International 2019). Additionally, in 2016, the total area exploited for organic agriculture in China was 2.3 million hectares; this represents almost onehalf of the 4.9 million hectares of Asia's agricultural land (FiBL and IFOAM-Organics International 2019). Projections therefore suggest that China's level of organic food consumption in coming years will be considerable. Nonetheless, within the literature, the factors that affect Chinese consumers' organic food purchase behavior remain unclear.

\section{Literature review}

Numerous studies explore consumer purchase intention and purchase decision within the context of "green" or organic food; these take place within a range of study backgrounds and exploit various theory of planned behavior (TPB) elements (e.g., attitude, subjective norms, and perceived behavior control [PBC]) (Hasan and Suciarto 2020; Kumar and Smith 2018; Sultan et al. 2020; Yadav and Pathak 2016). However, the results of some meta-analyses reveal that in terms of the original TPB, subjective norms are thought to have the poorest effect when assessing intention (Armitage and Conner 2001; Krueger Jr. et al. 2000; Sheppard et al. 1988). Rather than adopt the original TPB, one can more effectively assess consumer intention to purchase organic food by using a modified TPB and the factors therein, via the most robust predictive power of attitude (Han and Stoel 2016; Kim et al. 2013; Ünal et al. 2019). Inspired by this suggestion, researchers now extensively leverage modified forms of the TPB to study organic/green/ local food purchase behavior, in an attempt to delve into interrelation among variables regarding attitude, subjective norms, and PBC (Lin et al. 2012; Paul et al. 2016; Ritter et al. 2015; Ünal et al. 2019). While the power of subjective norms to predict consumer purchase attitude is identified in a variety of study contexts (e.g., India, Finland, and the United States) (Han and Stoel 2016; Singh and Verma 2017; Tarkiainen and Sundqvist 2005), the predictive power of subjective norms with respect to Chinese consumer attitude toward the purchase of organic food has been rarely studied. Thus, an in-depth exploration of whether consumer purchase attitude can be significantly predicted by subjective norms is indeed worthwhile.

Besides employing a modified TPB to study consumer purchase intention and purchase decision, more scholars have started to determine the roles of revealed information and knowledge in shaping consumer purchase attitude, in accordance with the alphabet theory (Zepeda and Deal 2009). It is suggested that revealed information and knowledge relating to organic food effectively impact consumer purchase attitude with respect to specific products and then stimulate consumer purchase intention (Kim and Bonn 2015; McClure and Seock 2020; Teng and Wang 2015; Xie et al. 2015). To be specific, sufficient information exposure can help build up trust and a positive attitude toward the purchase of organic food products (Gracia and de Magistris 2008; Żakowska-Biemans 2011). Likewise, the literature suggests that consumers are inclined to hold a more positive attitude toward products after acquiring relevant attituderelated knowledge (Chen and Tung 2014; Ellis and Thompson 2018; Nguyen et al. 2019); however, as certain studies reveal, Chinese consumers often fail to differentiate green food from organic food. Additionally, very few of these studies derive insights 
into the significance of organic food in China. Nevertheless, Chinese consumers do ultimately purchase organic food (Bekele et al. 2017; McCarthy 2015; Xie et al. 2015). It is therefore suggested that revealed information and knowledge-two critical factors that relate to subjective norms-should be fully and jointly explored in terms of their effect on Chinese consumer attitude vis-à-vis the purchase of organic food. This objective currently stands as a critical gap in the research into organic food purchase behavior.

As mentioned, a growing number of scholars have started to use a modified TPB to extend the original TPB into novel areas and, in the process, contribute to the literature. For organic/green/local/eco-friendly products purchase behavior, studies indicate that health consciousness, environmental/safety concerns, social norms, healthy lifestyle, and animal welfare are the most common factors that significantly affect consumer purchase intention (Arvola et al. 2008; Liu et al. 2012; Maichum et al. 2016; Paul et al. 2016; Rohman et al. 2020). In the current study, to delve into Chinese consumer intention to purchase organic food (and hence extend the TPB within the Chinese context), we critically introduce the concept of food therapy culture, which is deeply rooted in Chinese culture. Food therapy culture refers to a conventional daily healthcare regimen that involves the consumption of natural and healthier food; compare this lifestyle, for example, to one where modern pharmaceuticals are taken to address daily healthcare needs (Deng et al. 2012). Studies suggest that among Chinese consumers, food therapy culture correlates strongly with Chinese herbal medicine purchase (Cai, S.F. (2009). The development and research on nutritional therapy soup and diet of Hong kong [Unpublished master's thesis], Guangzhou University of Chinese Medicine; Jiao, T.Y. (2015). Visualization design of diet and health information based on sub-healthy people [Unpublished master's thesis], Kunming University of Science and Technology; Wei, X.B. (2016). Investigating the influencing factors of purchase organic agriculture food: An example of Huzhou [Unpublished master's thesis], South China Agriculture University; Liu et al. 2015). Since Chinese herbal medicine bears attributes that very much align with the definition of organic food (e.g., more natural, healthier, and without side effects of chemical components) (Wu and Chen 2017; Yao et al. 2012), it is assumed that consumers willing to purchase Chinese herbal medicines might also intend to purchase organic food. Besides, in the literature, studies that delve into Chinese consumer intention to purchase organic food have been rarely conducted from the perspective of local culture. Given this dearth of research, the current study looks to provide insights into the impact of food therapy culture on Chinese consumer intention to purchase organic food.

Moreover, extensive studies explore, on the basis of the TPB, a range of variables that affect consumer intention to purchase organic/green/local/eco-friendly products (Gad Mohsen and Dacko 2013; Kumar and Smith 2018; Xu et al. 2020a; Yadav and Pathak 2016). In marketing studies, for instance, purchase intention is extensively researched as a mediator of relationships between a variety of purchase factors (e.g., environmental concern, perceived knowledge, social norms, and perceived usefulness) and purchase behavior/decision with regard to eco-friendly products (Jaiswal and Kant 2018; Lim et al. 2016; Liu et al. 2012; Zarei et al. 2019). However, the mediating role of purchase intention when applying the TPB is far from being exhaustively studied, especially in terms of organic food purchase behavior among Chinese consumers. The literature 
does not fully explore the mediating role of purchase intention in the relationships between purchase factors (e.g., purchase attitude, PBC, and food therapy culture) and organic food purchase decision. It is this research problem that we identify herein and explore. In brief, Fig. 1 details the current study's proposed conceptual framework.

The current study makes several contributions to the literature. First, this study leverages two theories-namely, a modified TPB and the alphabet theory-and it further explores the role of subjective norms in influencing Chinese consumer attitude toward the purchase of organic food in China; this is something that researchers have scarcely addressed. Second, we also look to examine the effects of revealed information and knowledge on Chinese consumer attitude toward the purchase of organic food, on which there is also a dearth of research. More specifically, concerned with the important role of purchase attitude in shaping consumer purchase intention, we explore the critical roles of subjective norms, revealed information, and knowledge in the formation of Chinese consumer attitude toward the purchase of organic food; we also identify the most significant predictors of purchase attitude among the three aforementioned critical elements. Third, we examine food therapy culture as an essential purchase factor, from the perspective of local culture; we do so to more effectively deepen our understanding of the Chinese consumer intention to purchase organic food and also extend the TPB into novel areas. Finally, we extensively determine the mediating effect of purchase intention on the relationships between purchase factors (i.e., purchase attitude, $\mathrm{PBC}$, and food therapy culture) and purchase decision.

\section{Theoretical background and hypothesis development Modified theory of planned behavior and purchase attitude}

Icek Ajzen originally proposed the TPB in 1985, as an extension of the theory of reasoned action (Ajzen 1991; Fishbein and Ajzen 1975). The TPB refers to a theoretically structured framework that assesses and explains human behavior in terms of beliefs and attitudes (Ajzen 1991). Based on the TPB, Fishbein and Ajzen (2011) propose the reasoned action model (Fig. 2). Compared to the original TPB, this

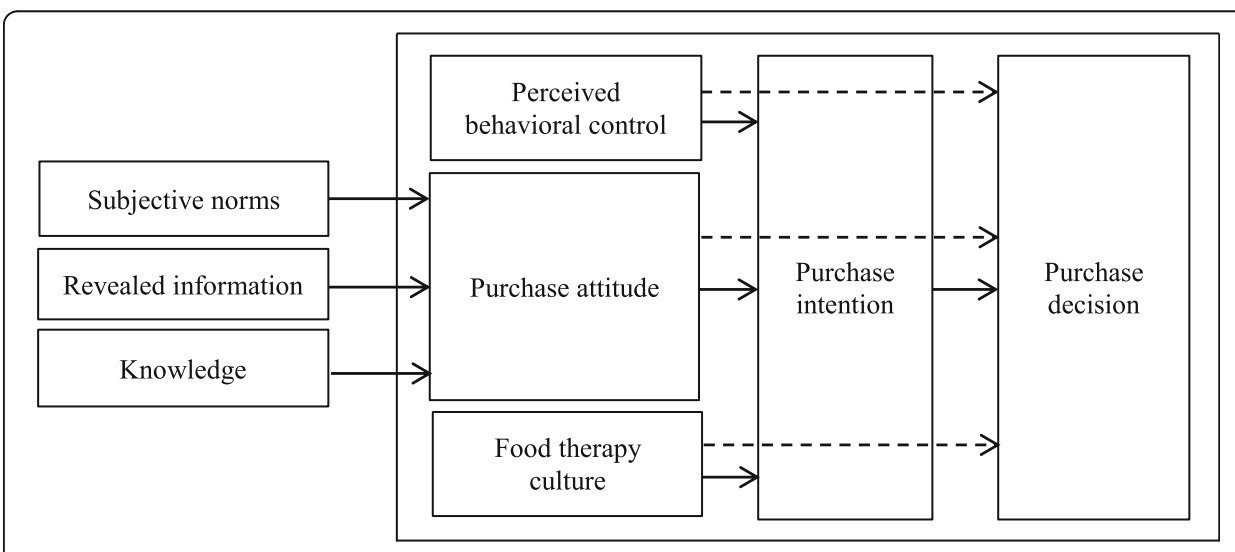

Fig. 1 Conceptual framework 
model introduces background factors that impose upon human beliefs; moreover, actual control is implemented in the relationships between perceived behavioral control and behavior.

In the TPB, subjective norms (i.e., perceived norms) represent perceived social influences or pressures; these refer to opinions and, to some extent, the approval of family, friends, co-workers, and any other person whom one trusts (Ajzen 1985). In marketing studies, more and more scholars have started to explore intercorrelations among subjective norms, $\mathrm{PBC}$, and attitude, across a range of study contexts; each of these studies leverages a modified TPB (Lin et al. 2012; Paul et al. 2016; Ritter et al. 2015; Ünal et al. 2019). By applying a modified TPB, these researchers find that subjective norms have an impact on consumer attitude that greatly exceed that on consumer purchase intention (e.g., customers' acceptance of airline B2C, battery-electric vehicle purchase intention, and local/street food purchase behavior) (Kim and Lennon 2008; Schmalfuß et al. 2017; Shin and Hancer 2016). Table 1 lists other studies that discuss the predictive power of subjective norms on consumer attitude.

As the studies listed in Table 1 suggest, consumer purchase attitude is significantly predicted by subjective norms, across a variety of study contexts (e.g., India, the United States, and European countries). Meanwhile, in terms of the current study context, the predictive power of subjective norms with respect to consumer purchase attitude (in terms of studying organic food purchases) remains unknown. Accordingly, with the support of the literature, we propose the following hypothesis.

Hypothesis 1: Subjective norms significantly influence consumer attitude toward the purchase of organic food.

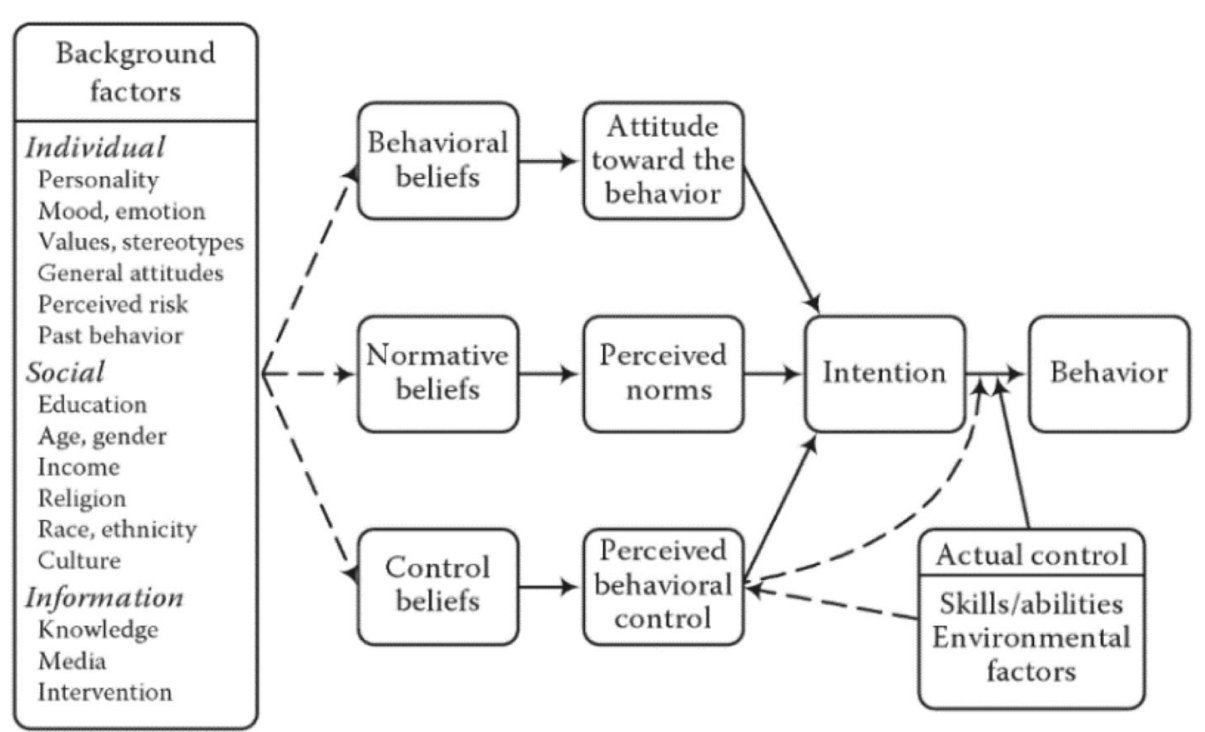

Fig. 2 Theoretical framework of the reasoned action model (modified TPB) 
Table 1 Notable research on subjective norms affecting purchase attitude

\begin{tabular}{|c|c|c|}
\hline Research topic & Citation & Country context \\
\hline $\begin{array}{l}\text { Consumers' attitude and intention toward organic } \\
\text { food purchase }\end{array}$ & Irianto (2015) & Indonesia \\
\hline $\begin{array}{l}\text { Consumers' actual buying behavior toward organic } \\
\text { food products }\end{array}$ & Singh and Verma (2017) & India \\
\hline $\begin{array}{l}\text { The effect of social norms and product knowledge on } \\
\text { purchase of organic cotton }\end{array}$ & Han and Stoel (2016) & The United States \\
\hline $\begin{array}{l}\text { Impact of culture, behavior, and gender on green } \\
\text { purchase intention }\end{array}$ & Sreen et al. (2018) & India \\
\hline Application of the TPB to green hotel choice & Han et al. (2010) & The United States \\
\hline Predicting organic food consumption, based on the TPB & Scalco et al. (2017) & European Union \\
\hline $\begin{array}{l}\text { Subjective norms, attitudes, and intentions of Finnish } \\
\text { consumers in buying organic food }\end{array}$ & Tarkiainen and Sundqvist (2005) & Finland \\
\hline $\begin{array}{l}\text { The role of subjective norms in the TPB, in the context } \\
\text { of organic food consumption }\end{array}$ & Al-Swidi et al. (2014) & Pakistan \\
\hline
\end{tabular}

The alphabet theory and purchase attitude

Zepeda and Deal first proposed the alphabet theory, in 2009; it is a revised theory based on value-belief-norm theory (Stern et al. 1999) and attitude-behavior-context theory (Guagnano et al. 1995). The alphabet theory stresses that knowledge, information seeking, and habit are critical to clarifying consumer preference-in this case, toward organic and local food. On the whole, the alphabet theory can elucidate correlations among variables (e.g., attitude, information seeking, and knowledge). Figure 3 shows the full conceptual framework of the alphabet theory.

Numerous studies emphasize the critical roles of revealed information and knowledge in influencing consumer attitude about specific products (Fiore et al. 2005; Mitchell and Boustani 1994; Nitse et al. 2004). In the current study, revealed information refers to any product or service that is considered a valuable indicator that shapes, guides, and builds a specific purchase attitude toward market products and services (Kim and Lennon 2000). While product knowledge within consumer perception primarily refers to product-related information stored in one's memory, such information could also include brand, product, attribute, evaluation, usage situation, and price (Vanhuele and

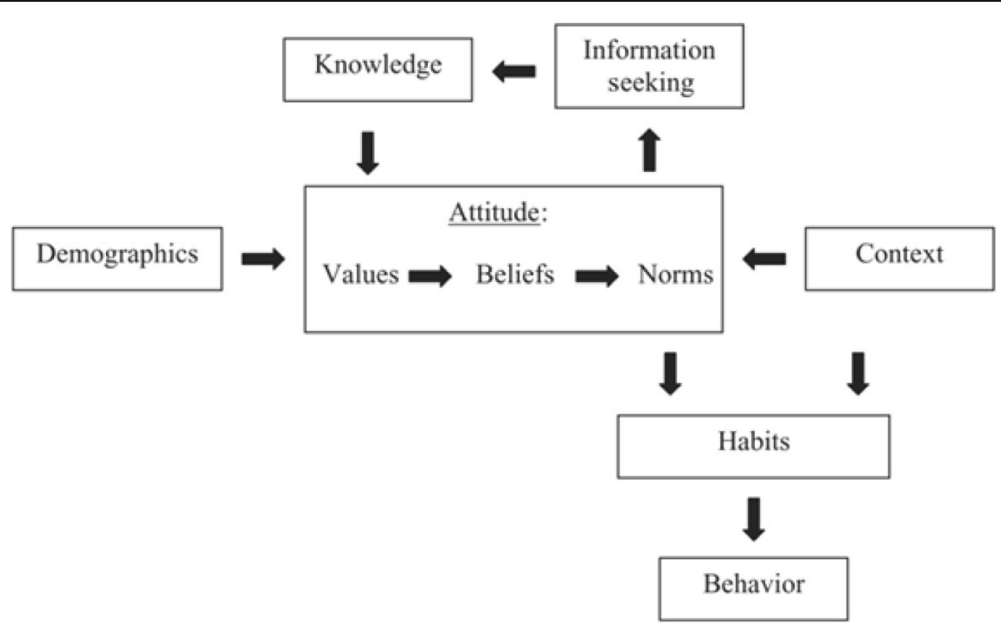

Fig. 3 Theoretical framework of the alphabet theory 
Drèze 2002). It is noteworthy that consumers' product knowledge accumulates via information searching and from their post-purchase experiences, as well as from advertisements, interactions with salespersons, and a range of usage situations (Alba and Hutchinson 2000). Given the interrelationships between revealed information and knowledge, researchers tend to discuss these two elements together in various study contexts.

With respect to food purchase behavior, Silayoi and Speece (2004) state that the informational element is an important factor that influences consumers' food purchase choices. Similarly, Cranage et al. (2005) suggest that delivering appropriate nutritional information both visually and verbally (i.e., on food packaging) impacts consumers' purchase attitude and their decision-making process significantly. Moreover, Chen and Tung (2014) also propose that brand information acquired from electronic word of mouth (eWOM) sources positively impacts consumer purchase attitude with respect to a specific brand.

Aside from discussions of the critical role of revealed information, there are various elucidations of the importance of knowledge in shaping consumer purchase attitude. According to Basha et al. (2015), regardless of whether product knowledge affects consumer perception positively or adversely, the more valuable the knowledge is that consumers receive, the more likely they will develop either favorable or unfavorable attitudes toward the products involved. Specifically, research findings related to eco-friendly purchase behavior in India indicate that subjective environmental knowledge significantly influences consumer purchase attitude toward green products (Yadav and Pathak 2016). In line with the current study, Ritter et al. (2015) suggest that subjective knowledge acquisition-as a critical motivating factor-effectively impacts consumer attitude toward green products in northern Brazil. Regarding food purchase behavior, Brugarolas et al. (2010) reveal that Spanish consumers' level of perceived knowledge with respect to organic food strictly relates to their attitude of acceptance for organic wine. Likewise, Ellis and Thompson (2018) also state that wine knowledge types are vital predictors of variety-seeking behavior with respect to wines: Consumers confident in their wine knowledge are more inclined to exhibit a positive attitude in such variety-seeking behavior.

Overall, given the critical roles within the alphabet theory of information and knowledge in shaping consumer attitude toward organic/local food, the alphabet theory is better able to provide a solid theoretical support by which to delve into the interrelations among purchase attitude, revealed information, and knowledge in research into Chinese consumer attitude toward the purchase of organic food. Accordingly, we propose the following hypotheses.

Hypothesis 2: Revealed information significantly influences consumer attitude toward the purchase of organic food.

Hypothesis 3: Knowledge significantly influences consumer attitude toward the purchase of organic food.

\section{Perceived behavioral control and purchase intention}

PBC is a critical TPB variable. It can be defined as the ability to control specific behavior-in other words, the perceived "difficulty of declining the invitation" (Ajzen 1985: p. 
26). Since $P B C$ is very much considered an effective variable in affecting individuals' ability to perform a behavior, it is not surprising that numerous marketing studies that investigate $\mathrm{PBC}$ 's predictive power link $\mathrm{PBC}$ to behavioral intention (Delafrooz et al. 2011; Hsu et al. 2017; Kim et al. 2013). According to Ajzen (1991), PBC categorizes internal control factors (e.g., skills, abilities, power of will, and compulsion) and external control factors (e.g., time, opportunities, and willingness from others). On that basis, numerous studies touch upon relationships between PBC and consumer purchase intention. Delafrooz et al. (2011) show that self-efficacy, cost, and trust are critical internal control factors that closely relate to consumers' online purchase intention. In contrast, some study results suggest that external control factors are more likely to influence consumer purchase intention. Jin and Hye Kang (2011), for example, prove that among the Chinese, individual-level controllability toward purchase behavior effectively impacts purchase intention toward U.S. apparel brands. Numerous scholars support the role of external PBC in impacting consumer shopping behavior (e.g., Fowler et al. 2012; Hsu et al. 2017; Son et al. 2013).

Furthermore, the predictive power of $\mathrm{PBC}$ very much relates to healthy/green purchase intention/behavior (Brouwer and Mosack 2015; Dean et al. 2008; Xu et al. 2020b). Thus, PBC should be further explored in tandem with consumer purchase intention, specifically in terms of organic food purchase behavior. We put forward the following hypothesis.

Hypothesis 4: PBC significantly influences consumer purchase intention regarding organic food.

\section{Purchase attitude and purchase intention}

Within the context of the TPB, attitude refers to an individual's attitude or opinionthat is to say, whether a specific behavior is good or bad, positive or negative, or favorable or unfavorable (Ajzen 1991). According to Cheng et al. (2006), individuals are inclined to hold a positive attitude when a positive outcome is expected; thus, consumers are more likely to act on the basis of such a positive attitude. In marketing studies, attitude within the TPB closely relates to purchase intention, and numerous studies prove that in various shopping situations, consumer purchase attitude either positively or adversely affects purchase intention vis-à-vis specific products (Hartmann and Apaolaza-Ibáñez 2012; Lee et al. 2015; Phua and Kim 2018; Pisitsankkhakarn and Vassanadumrongdee 2020).

Specifically, various studies show that purchase attitude imposes a significant mediating effect on relationships between other purchase factors and purchase intention. For example, Han et al. (2010) argue that consumer attitude effectively mediates the relationship between subjective norms and green hotel visit intention. In line with that study, Chen and Tung (2014) illustrate that consumer attitude toward green hotels plays a mediating role in the relationship between environmental concern and intention to visit green hotels. Moreover, consumer attitude also directly impacts green product purchase intention (Cerri et al. 2018). Concerning the important ways in which consumer attitude influences consumer purchase intention, still other studies relate to green/organic food purchase intention. Lin and Huang (2012) claim that achieving a 
full understanding of consumer purchase attitude can help policy makers, producers, and marketers promote green purchase habits and induce further consumption of green/organic products.

Recent studies examine the role of attitude in the TPB to deeply understand its predictive power toward organic food purchase intention. Various studies prove that consumer attitude can influence consumer purchase intention, either directly, or indirectly through alternative variables (e.g., health consciousness, environmental concern, food safety, and taste) (Hsu et al. 2017; Lee et al. 2015; Nguyen et al. 2019; Pham et al. 2018). Thus, we expect that purchase attitude can predict Chinese consumers' intention to purchase organic food. Thus, we set forth the following hypothesis.

Hypothesis 5: Purchase attitude significantly influences consumer purchase intention toward organic food.

\section{Food therapy culture and purchase intention}

Numerous scholars suggest a variety of TPB-based variables to better examine consumer purchase intention and purchase behavior; in the process, they extend the TPB into novel areas, in a variety of academic disciplines and contexts (Liang 2016; Liu et al. 2012; Paul et al. 2016). We put forward that in China, food therapy culture is an alternative purchase factor that influences consumer purchase intention. According to $\mathrm{Xu}$ (2003), in China, food therapy culture refers to a conventional lifestyle in which human health is improved and maintained by consuming natural and edible goods (e.g., natural herbs), rather than by taking modern pharmaceuticals. Food therapy, as a part of traditional Chinese medicine, can help an individual achieve physiological equilibrium, optimize organ function, prevent potential diseases, and improve sub-health status, all without the side effects associated with modern pharmaceuticals (Deng et al. 2012; Wu and Chen 2017; Yao and Wu 2019). In China, food therapy culture is, in essence, one of the most readily embraced means of enhancing one's lifestyle.

Relatedly, Xu (2003) claims that many elderly individuals in China look to meet their food therapy needs by consuming traditional Chinese herbal medicine; they often make this decision in consideration of the potential side effects of modern pharmaceuticalsa point on which herbal medicine and traditional Chinese medical treatments diverge from modern medicine. Furthermore, Liu et al. (2015) propose that middle-class families in China are more passionate about purchasing organic and vegetarian food as part of their daily healthcare regimen. Moreover, according to (Chen, Y.X. (2012). Studies on impacts factors of Chinese herbal medicine consumers' behavior [Unpublished doctoral dissertation], Fujian Agriculture and Forestry University), most Chinese believe that such a healthy eating lifestyle is significantly superior to taking medicine, whether to cure disease or achieve sound day-to-day health. Based on its characteristics, organic food in China has many of the same attributes as Chinese herbal medicine (e.g., has a natural, nonchemical effect, and is not contaminated). The current study assumes that consumers who prefer to purchase Chinese herbal medicine as part of their daily food therapy regimen may also intend to purchase organic food in the future.

For this reason, we study food therapy culture as a critical driving factor, from the perspective of local culture; we do so to delve into Chinese consumer intention to 
purchase organic food in China and, by adding an alternative purchase factor, extend the TPB into novel areas. On that basis, we propose the following hypothesis.

Hypothesis 6: Food therapy culture significantly influences consumer purchase intention toward organic food.

\section{Mediating role of purchase intention}

Purchase intention has been extensively studied as a mediator of the relationships between a variety of purchase factors (e.g., environmental concerns, perceived knowledge, social norms, and perceived usefulness) and purchase behavior/decision with regard to eco-friendly products (e.g., Jaiswal and Kant 2018; Lim et al. 2016; Liu et al. 2012; Zarei et al. 2019). Concerned with the essential mediating role of purchase intention when studying both the consumer purchase decision and the decision-making process, numerous studies attempt to identify more effective variables that positively impact the consumer purchase decision, chiefly by mediating the purchase intention with regard to organic food products.

According to Chen (2007), consumer intention to purchase organic food is significantly driven by a series of food motives (e.g., health, mood, convenience, personal need, and environmental protection) that indirectly influence the consumer purchase decision. Zhou et al. (2013) also indicate that the consumer intention to purchase organic food significantly mediates the relationships between purchase factors (e.g., attitude, injunctive norms, $\mathrm{PBC}$, and personal values) and purchase decision. Additionally, several studies conclude that a lack of trust, labeling issues, lower availability, and premium prices are considered critical variables that adversely and indirectly affect consumer purchase decision with respect to organic food, through the mediating role of purchase intention (Aslihan Nasir and Karakaya 2014; Tung et al. 2012; Xie et al. 2015). Based on a rational discussion concerning the mediating role of purchase intention, we expect to find that, in China, consumer purchase intention can significantly mediate the relationship between purchase factors (i.e., purchase attitude, PBC, and food therapy culture) and purchase decision with regard to organic food. Thus, we propose the following hypotheses.

Hypothesis 7(a): Purchase intention significantly mediates the relationship between PBC and purchase decision regarding organic food.

Hypothesis 7(b): Purchase intention significantly mediates the relationship between purchase attitude and purchase decision regarding organic food.

Hypothesis 7(c): Purchase intention significantly mediates the relationship between food therapy culture and purchase decision regarding organic food.

\section{Method}

\section{Study sample and procedures}

Our study sample was selected through purposive sampling, while bearing in mind the homogeneous attribute of the target participants: Specifically, the target population of the current study comprises organic food consumers in Beijing, China. For this reason, all participants were selected on the basis of having previously purchased organic food 
and, to some extent, having a basic understanding of organic food. Thus, for our purpose, we consider purposive sampling the best sampling method. Paper-based survey questionnaires were distributed to organic food consumers in supermarkets that have organic food sections (e.g., BHG Market Place, 7 Fresh supermarket, Hema Supermarket, and Jenny Lou's supermarket).

We determined that a sample size of $n=384$ would suffice; this number is based on geographical distribution and city population and calculated at the $95 \%$ confidence level with a 5\% margin of error (Krejcie and Morgan 1970). Data were collected in two stages. In the first stage, 384 paper questionnaires were distributed, and 382 were returned (return rate: 99.5\%). Among these 382 records, we deemed 296 valid, after deleting outliers and those with missing values (effective response rate: $77.5 \%$; nonresponse rate: $22.5 \%)$. To preclude data bias and elevate the effective response rate, in the second stage, 86 paper questionnaires were distributed, and we achieved a 100\% return rate; of these, 14 were valid (effective response rate: 16.3\%). As such, we elevated the survey response rate to $81.15 \%$, with 310 valid records. Moreover, a sample comprising 310 records is considered sufficient to conduct structural equation modeling (Westland 2010). Table 2 lists the descriptive statistics of our study participants.

Among the 310 participants, 224 are female (72.3\%), and 86 male (27.7\%), indicating that most organic food purchasers are female. The average age was 34.5 years (standard deviation $=9.42$; range: $45-54$ years). Furthermore, $54.2 \%$ of the participants are undergraduate degree holders, and $27.7 \%$ of them are postgraduate degree holders; these findings suggest that most organic food purchasers are considerably educated.

Although we significantly increased our valid response rate by undertaking a second stage of data collection, we remained concerned about the $18.85 \%$ nonresponse rate (i.e., 72 invalid records). Table 3 presents the basic nonresponse information from invalid records.

From the statistical results in Table 3, we can draw some useful findings and conclusions as follows.

Table 2 Descriptive statistics of the study participants $(n=310)$

\begin{tabular}{|c|c|c|}
\hline Item & Number & Proportion \\
\hline \multicolumn{3}{|l|}{ Gender } \\
\hline Female & 224 & $72.3 \%$ \\
\hline Male & 86 & $27.7 \%$ \\
\hline \multicolumn{3}{|c|}{ Age } \\
\hline $18-24$ & 35 & $11.3 \%$ \\
\hline $25-34$ & 62 & $20.0 \%$ \\
\hline $35-44$ & 81 & $26.1 \%$ \\
\hline $45-54$ & 103 & $33.2 \%$ \\
\hline$\geq 55$ & 29 & $9.4 \%$ \\
\hline \multicolumn{3}{|c|}{ Education } \\
\hline Secondary school and below & 56 & $18.1 \%$ \\
\hline Undergraduate & 168 & $54.2 \%$ \\
\hline Postgraduate & 86 & $27.7 \%$ \\
\hline
\end{tabular}


Table 3 Basic information on categories of nonresponses $(n=72)$

\begin{tabular}{llll}
\hline Questionnaire section & Item & Nonresponse number & Nonresponse proportion \\
\hline Demographic section & Gender & 4 & $5.6 \%$ \\
& Age & 13 & $18.1 \%$ \\
& Education & 21 & $29.2 \%$ \\
SN & Q1 & 6 & $8.3 \%$ \\
& Q2 & 13 & $18.1 \%$ \\
& Q4 & 7 & $9.7 \%$ \\
RI & Q3 & 11 & $15.3 \%$ \\
& Q4 & 8 & $11.1 \%$ \\
KNWGE & Q2 & 3 & $4.2 \%$ \\
& Q3 & 2 & $2.8 \%$ \\
PBC & Q1 & 6 & $8.3 \%$ \\
& Q3 & 14 & $19.4 \%$ \\
& Q5 & 3 & $4.2 \%$ \\
PA & Q3 & 4 & $5.6 \%$ \\
FTC & Q3 & 2 & $2.8 \%$ \\
& Q4 & 3 & $4.2 \%$ \\
\hline
\end{tabular}

Notes. $S N=$ subjective norms, $R I=$ revealed information, $K N W G E=$ knowledge, $P B C=$ perceived behavioral control, $P A=$ purchase attitude, $F T C=$ food therapy culture

(1) Most of the participants left "education background" in the demographic information section blank (29.2\%); this suggests that some of them were reluctant to disclose their education information. Hence, in subsequent studies, confidentiality should be stressed more clearly in the cover letter of the questionnaire.

(2) Question 2 in the item "subjective norms" and question 3 in the item "revealed information" were often left unanswered (18.1\% and $15.3 \%$ of all questionnaires, respectively). These two questions were relatively long and likely caused fatigue among some participants. Thus, future research should use questionnaires that feature shorter questions.

(3) In all $19.4 \%$ of participants incompletely answered question 3 in the item "perceived behavioral control"; they may not have understood the full meaning of "resources" in this question. Thus, future research should be careful to explain what the term "resources" means, so as to eliminate potential misunderstandings among participants.

\section{Measures}

The questionnaire was originally designed in English. Since the target participants are Chinese, the questionnaire was translated into Mandarin by an expert. All information were captured through a five-point Likert scale ranging from 1 (strongly disagree) to 5 (strongly agree).

\section{Subjective norms}

We captured information on subjective norms via the four-item scale following Yadav and Pathak (2016). One sample item is "My attitude toward purchasing organic food is impacted by my family." The composite Cronbach's $\alpha$ for this scale reaches 0.913 . 


\section{Revealed information}

We captured data on revealed information via the four-item scale developed by Ritter et al. (2015). A sample item is that "Organic food-related information is critical to my attitude toward purchasing organic food.” The composite Cronbach's $\alpha$ for this scale is 0.890 .

\section{Knowledge}

We captured knowledge via the four-item scale from Ellis and Thompson (2018), a sample item of which is "My attitude toward purchasing organic food is significantly impacted by my relevant knowledge." The composite Cronbach's $\alpha$ for this scale is 0.768 .

\section{Perceived behavioral control}

We determined PBC through the six-item scale developed by Paul et al. (2016). One sample item is "If I can make decision by my own, I am confident that I will purchase organic food." The composite Cronbach's $\alpha$ for this scale is 0.809 .

\section{Purchase attitude}

We captured purchase attitude data via the five-item scale developed by Chen (2007), one sample item of which is "Organic food has superior quality." The composite Cronbach's $\alpha$ for this scale is 0.750 .

\section{Food therapy culture}

We measured food therapy culture through the use of the five-item scale developed by (Chen, Y.X. (2012). Studies on impacts factors of Chinese herbal medicine consumers' behavior [Unpublished doctoral dissertation], Fujian Agriculture and Forestry University). A sample item of this scale is "I prefer selecting more natural and non-synthetic fertilizers food to fulfill my daily healthcare purposes." The composite Cronbach's $\alpha$ for this scale is 0.860 .

\section{Purchase intention}

We determined purchase intention via the four-item scale from Liang (2016). One sample item is "I am strongly willing to purchase organic food for my daily diet needs." The composite Cronbach's $\alpha$ for this scale is 0.835 .

\section{Purchase decision}

We measured purchase decision by using the four-item scale of Tariq et al. (2019). One sample item is "I used to purchase some organic food when shopping for food." The composite Cronbach's $\alpha$ for this scale is 0.860 .

\section{Results}

Discriminate validity analysis

To ensure the discriminate validity of the two proposed models, we undertake confirmatory factor analysis with Amos 24.0 to examine their fit indices. As Table 4 shows, both models 1 and 2 show good model fit. Accordingly, the discriminate validity of the two proposed models is supported. 
Table 4 Discriminate validity analysis results

\begin{tabular}{lllllll}
\hline Model & $\boldsymbol{x}^{2} / \boldsymbol{d f}$ & RMSEA & CFI & NFI & AGFI & GFI \\
\hline $\begin{array}{l}\text { Model 1 } \\
\text { (SN, RI, KNWGE, PA) }\end{array}$ & 1.758 & 0.050 & 0.974 & 0.941 & 0.908 & 0.930 \\
$\begin{array}{l}\text { Model 2 } \\
\text { (PA, PBC, FTC, PI, PD) }\end{array}$ & 2.574 & 0.071 & 0.926 & 0.886 & 0.831 & 0.862 \\
\begin{tabular}{l} 
Benchmark \\
\hline
\end{tabular} & $<5.0$ & $<0.05$ & $>0.9$ & $>0.9$ & $>0.8$ & $>0.8$ \\
\hline
\end{tabular}

Notes. $n=310$. SN = subjective norms; RI = revealed information; KNWGE = knowledge; $\mathrm{PA}=$ purchase attitude; $\mathrm{PBC}=$ perceived behavioral control; $\mathrm{FTC}=$ food therapy culture; $\mathrm{PI}=$ purchase intention; $\mathrm{PD}=$ purchase decision $R M S E A=$ root mean square error of approximation, $C F I=$ comparative fit index, $N F I=$ normed fit index, $A G F I=$ adjusted goodness of fit index, GFI = goodness of fit index

\section{Convergent validity analysis}

We determine the convergent validity of the constructs through composite reliability (CR) and average variance extracted (AVE). The results (see Table 5) suggest that all CR and AVE constructs reach the benchmark, and the CR and AVE should exceed 0.7 and 0.5, respectively (Fornell and Larcker 1981). Thus, the convergent validity of all the constructs is supported.

\section{Descriptive statistics and correlations}

Table 6 details the means, standard deviations, correlations, and composite reliability $(\alpha)$ of each variable. Consumer purchase attitude positively correlates with subjective norms $(r=0.20, p<0.01)$ and knowledge $(r=0.23, p<0.01)$, while purchase attitude does not significantly correlate with revealed information $(r=-0.06, p>0.05)$. Moreover, purchase intention correlates positively with $\mathrm{PBC}(r=0.70, p<0.01)$, purchase attitude $(r=0.51, p<0.01)$, and food therapy culture $(r=0.41, p<0.01)$. Finally, purchase intention correlates positively with purchase decision $(r=0.34, p<0.01)$.

\section{Hypothesis testing}

We examine hypotheses 1-6 through regression analysis in Amos 24.0; Table 7 shows the results. The findings with model 1 suggest that purchase attitude correlates significantly with each of subjective norms $(\beta=0.20, p<0.001)$ and knowledge $(\beta=0.25, p<0.001)$, but has no such significant correlation with revealed information $(\beta=-0.06, p>0.05)$. The findings with model 2 , on the other hand, indicate that purchase intention correlates significantly with each of $\mathrm{PBC}(\beta=0.70, p<0.001)$, purchase attitude $(\beta=0.18, p<0.01)$, and food therapy culture $(\beta=0.19, p<0.001)$. Accordingly, these results support hypotheses 1 , $3,4,5$, and 6; hypothesis 2 , on the other hand, is not supported.

In the current study, we use Amos 24.0 to explore the direct, indirect, and total effects and determine the mediating role of purchase intention in the relationships between purchase decision and each of PBC, purchase attitude, and food therapy culture. Table 8 shows that the indirect effects of $\mathrm{PBC}$ on purchase decision, as stimulated by purchase intention, are significant $(\beta=0.201, p<0.01)$; meanwhile, the direct effects of $\mathrm{PBC}$ on purchase decision, as stimulated by purchase intention, are insignificant $(\beta=0.024, p>0.05)$. These findings demonstrate that purchase intention fully mediates the relationship between PBC and purchase decision. Thus, hypothesis 7(a) is supported. The indirect effects of purchase attitude on purchase decision, as stimulated by purchase intention, are significant $(\beta=0.053$, $p<0.01)$, while the direct effects of the same are insignificant $(\beta=-0.025, p>0.05)$. The 
Table 5 Convergent validity analysis results

\begin{tabular}{|c|c|c|c|c|}
\hline Construct & Item & Standardized factor loading & CR & AVE \\
\hline \multirow[t]{4}{*}{ SN } & SN1 & 0.757 & 0.923 & 0.752 \\
\hline & SN2 & 0.880 & & \\
\hline & SN3 & 0.855 & & \\
\hline & SN4 & 0.965 & & \\
\hline \multirow[t]{4}{*}{$\mathrm{Rl}$} & Rl1 & 0.836 & 0.870 & 0.627 \\
\hline & $\mathrm{R} / 2$ & 0.753 & & \\
\hline & $\mathrm{RI3}$ & 0.685 & & \\
\hline & $\mathrm{R} \mid 4$ & 0.880 & & \\
\hline \multirow[t]{4}{*}{ KNWGE } & KNWGE1 & 0.734 & 0.824 & 0.539 \\
\hline & KNWGE2 & 0.726 & & \\
\hline & KNWGE3 & 0.757 & & \\
\hline & KNWGE4 & 0.720 & & \\
\hline \multirow[t]{5}{*}{ PA } & PA1 & 0.711 & 0.923 & 0.709 \\
\hline & PA2 & 0.959 & & \\
\hline & PA3 & 0.884 & & \\
\hline & PA4 & 0.789 & & \\
\hline & PA5 & 0.845 & & \\
\hline \multirow[t]{6}{*}{ PBC } & $\mathrm{PBC} 1$ & 0.783 & 0.896 & 0.590 \\
\hline & PBC2 & 0.737 & & \\
\hline & PBC3 & 0.694 & & \\
\hline & PBC4 & 0.734 & & \\
\hline & $\mathrm{PBC5}$ & 0.788 & & \\
\hline & PBC6 & 0.862 & & \\
\hline \multirow[t]{5}{*}{ FTC } & $\mathrm{FTC1}$ & 0.817 & 0.901 & 0.646 \\
\hline & FTC2 & 0.799 & & \\
\hline & FTC3 & 0.807 & & \\
\hline & FTC4 & 0.847 & & \\
\hline & FTC5 & 0.744 & & \\
\hline \multirow[t]{4}{*}{$\mathrm{PI}$} & PI1 & 0.738 & 0.858 & 0.601 \\
\hline & $\mathrm{Pl} 2$ & 0.793 & & \\
\hline & $\mathrm{Pl3}$ & 0.756 & & \\
\hline & $\mathrm{Pl} 4$ & 0.812 & & \\
\hline \multirow[t]{4}{*}{ PD } & PD1 & 0.904 & 0.917 & 0.736 \\
\hline & PD2 & 0.850 & & \\
\hline & PD3 & 0.763 & & \\
\hline & PD4 & 0.906 & & \\
\hline
\end{tabular}

Notes. $n=310$

$S N=$ subjective norms, $R I=$ revealed information, $K N W G E=$ knowledge, $P B C=$ perceived behavioral control, $P A$ $=$ purchase attitude, $F T C=$ food therapy culture, $P I=$ purchase intention, $P D=$ purchase decision

implication here is that purchase intention fully mediates the relationship between purchase attitude and purchase decision. Thus, hypothesis 7(b) is supported. Finally, food therapy culture is found to have significant indirect effects on purchase decision as stimulated by purchase intention $(\beta=0.057, p<0.01)$, while the direct effects of the same are insignificant $(\beta=0.105, p>0.05)$; this suggests that purchase intention fully mediates the relationship between food therapy culture and purchase decision. Hence, hypothesis 7 (c) is supported. 
Table 6 Means, standard deviations, and correlations among study variables

\begin{tabular}{lllllllllllll}
\hline Variable & $\mathbf{M}$ & SD & $\mathbf{1}$ & $\mathbf{2}$ & $\mathbf{3}$ & $\mathbf{4}$ & $\mathbf{5}$ & $\mathbf{6}$ & $\mathbf{7}$ & $\mathbf{8}$ & $\mathbf{9}$ & $\mathbf{1 0}$ \\
\hline 1. Gender & 1.72 & 0.45 & - & & & & & & & & \\
2. Age & 34.50 & 9.42 & 0.04 & - & & & & & & & \\
3. Edu & 1.49 & 0.50 & -0.04 & $-0.20^{* *}$ & - & & & & & & \\
4. SN & 4.18 & 0.68 & 0.01 & -0.09 & -0.02 & & & & & & \\
5. RI & 3.38 & 0.90 & 0.06 & -0.02 & 0.02 & 0.02 & & & & & \\
6. KNWGE & 3.95 & 0.87 & -0.04 & -0.05 & 0.02 & 0.05 & $0.15^{*}$ & & & & \\
7. PBC & 3.53 & 0.89 & 0.01 & -.0 .10 & -0.01 & $0.18^{* *}$ & -0.06 & $0.13^{*}$ & & & \\
8. PA & 4.17 & 0.63 & -0.01 & -0.05 & 0.01 & $0.20^{* *}$ & -0.06 & $0.23^{* *}$ & $0.57^{* *}$ & & \\
9. FTC & 3.48 & 0.62 & 0.04 & -0.07 & 0.09 & $0.14^{*}$ & 0.08 & -0.01 & $0.38^{* *}$ & $0.31^{* *}$ & \\
10. PI & 3.88 & 0.80 & -0.08 & -0.03 & $0.02^{*}$ & $0.15^{* *}$ & 0.01 & 0.02 & $0.70^{* *}$ & $0.51^{* *}$ & $0.41^{* *}$ & \\
11. PD & 3.81 & 0.78 & -0.08 & 0.00 & 0.03 & $0.13^{*}$ & 0.04 & -0.00 & $0.28^{* *}$ & $0.16^{* *}$ & $0.25^{* *}$ & $0.34^{* *}$ \\
\hline
\end{tabular}

Notes. $n=310$. Gender was coded as follows: 1 = male, 2 = female; Education level was coded as follows: $1=$ undergraduate and below, 2 = master degree and above

$S N=$ subjective norms, $R I=$ revealed information, $K N W G E=$ knowledge, $P B C=$ perceived behavioral control, $P A=$ purchase attitude, $F T C=$ food therapy culture, $P I=$ purchase intention, $P D=$ purchase decision ${ }^{*} p<0.05,{ }^{* *} p<0.01$. Two-tailed test

\section{Discussion}

\section{Theoretical implications}

The current study innovatively applies both a modified TPB and the alphabet theory to comprehensively study consumer purchase intention and purchase behavior toward organic food, within the context of Chinese consumers in China. Our study results clearly demonstrate that consumer attitude toward the purchase of organic food tends to be highly motivated by subjective norms and knowledge; they also emphasize that knowledge critically impacts consumer purchase attitude. In terms of the magnitude of impact, consumer attitude is followed by subjective norms, and revealed information is not found to correlate with consumer purchase attitude.

Moreover, consumer intention to purchase organic food closely relates to $\mathrm{PBC}$, purchase attitude, and food therapy culture; among these, $\mathrm{PBC}$ critically impacts purchase intention, and in terms of the magnitude of impact, $\mathrm{PBC}$ is followed by food therapy culture and purchase attitude. Furthermore, the results of our mediating test indicate that purchase intention plays an effective mediating role in the relationships between purchase decision and each of purchase attitude, PBC, and food therapy culture. Given our results, the current study makes several contributions to the marketing literature, especially that on consumer purchase behavior.

Table 7 Regression analysis results (Hypotheses 1-6)

\begin{tabular}{|c|c|c|c|c|c|c|c|}
\hline \multirow[t]{2}{*}{ Model 1} & \multicolumn{3}{|c|}{ Purchase attitude } & \multirow[t]{2}{*}{ Model 2} & \multicolumn{3}{|c|}{ Purchase intention } \\
\hline & Estimate & SE & $t$-value & & Estimate & SE & $t$-value \\
\hline$\overline{S N}$ & $0.20^{* * *}$ & 0.05 & 3.34 & PBC & $0.70^{* * *}$ & 0.09 & 9.03 \\
\hline $\mathrm{Rl}$ & -0.06 & 0.04 & -1.34 & PA & $0.18^{* *}$ & 0.04 & 3.18 \\
\hline KNWGE & $0.25^{* * *}$ & 0.07 & 3.84 & FTC & $0.19^{* * *}$ & 0.03 & 3.68 \\
\hline
\end{tabular}

Notes. $n=310$

$S N=$ subjective norms, $R I=$ revealed information, $K N W G E=$ knowledge, $P B C=$ perceived behavioral control, $P A$ $=$ purchase attitude, $F T C=$ food therapy culture, $S E=$ standard error

${ }^{* *} p<0.01,{ }^{* * *} p<0.001$ 
Table 8 Direct, indirect, and total effects analysis results (Hypotheses 7(a)-7(c))

\begin{tabular}{lllll}
\hline Path & Direct effects & Indirect effects & Total effects & Mediation \\
\hline $\mathrm{PBC} \rightarrow \mathrm{Pl} \rightarrow \mathrm{PD}$ & 0.024 & $0.201^{* *}$ & $0.225^{* *}$ & Supported (full mediation) \\
$\mathrm{PA} \rightarrow \mathrm{Pl} \rightarrow \mathrm{PD}$ & -0.025 & $0.053^{* *}$ & $0.028^{* *}$ & Supported (full mediation) \\
$\mathrm{FTC} \rightarrow \mathrm{Pl} \rightarrow \mathrm{PD}$ & 0.105 & $0.057^{* *}$ & $0.162^{* *}$ & Supported (full mediation) \\
\hline$n=310$ & & \\
Notes.PBC = perceived behavioral control, $P A=$ purchase attitude, $F T C=$ food therapy culture, $P I=$ purchase intention, \\
$\begin{array}{l}P D=\text { purchase decision } \\
{ }^{* *} P<0.01\end{array}$
\end{tabular}

First, this study applies both a modified TPB and the alphabet theory to delve into the critical variables that impact consumer attitude toward the purchase of organic food, and to accurately identify those variables that critically impact consumer purchase attitude. Previous studies that leverage a modified TPB or the alphabet theory separately examine consumer purchase attitude through the lens of subjective norms, revealed information, and knowledge, in a range of study contexts (e.g., Chen and Tung 2014; Ellis and Thompson 2018; Irianto 2015). However, the current study makes mixed use of a modified TPB and the alphabet theory to fully and simultaneously explore consumer attitude toward the purchase of organic food, from the perspectives of subjective norms, revealed information, and knowledge. Additionally, this study draws comparisons of the three aforementioned critical variables-something scarcely done before.

Second, this study is the first to consider food therapy culture an essential purchase factor from the perspective of local culture. It looks to achieve a deeper understanding of the Chinese consumer intention to purchase organic food in China, and extends the TPB to study consumer organic food purchase behavior. The literature focuses primarily on the impact of food therapy culture on the purchase of traditional Chinese herbal medicine, rather than on potential relationships between food therapy culture and purchase decision on organic food purchase among Chinese consumers (Xu 2003). Our study results indicate that food therapy culture significantly predicts Chinese consumer purchase intention toward organic food, and for this reason can be considered a contributor to the literature.

Third, this study contributes to the literature in how it examines the mediating role of purchase intention. This study is the first to determine the concurrent mediating effect of purchase intention on the relationships between purchase factors (i.e., purchase attitude, $\mathrm{PBC}$, and food therapy culture) and purchase decision: A dearth of studies in the literature look to determine the mediating role of purchase intention by fully involving the three aforementioned factors, especially in the context of organic food purchase behavior (e.g., Tung et al. 2012). Our study results show that purchase intention significantly mediates the relationships between each of purchase attitude, PBC, and food therapy culture, and purchase decision regarding organic food, and thus imply that the effects of these three factors on consumer purchase decision vis-à-vis organic food are more likely to rely on the mediating role of purchase intention.

\section{Practical implications}

Besides theoretical contributions, the current study also contributes to the literature with several practical implications with respect to encouraging consumer purchase 
intention and purchase decision vis-à-vis organic food; as such, marketers and policy makers can reference our findings as they craft policies by which to sustainably develop the organic food market. First, our study results reveal that consumer attitude toward the purchase of organic food is obviously motivated by subjective norms and knowledge; thus, marketers and policy makers could leverage these two critical points and launch effective marketing campaigns to disseminate knowledge about (and the benefits of) organic food; such campaigns could enhance consumers' understanding of organic food and thus cultivate positive attitudes concerning its purchase. Additionally, concerning the significance of subjective norms, consumer purchase attitude tends to be impacted by family members, friends, and other people important to the consumer. Marketers could offer considerable discounts that attract consumers and encourage them to try organic food; by leveraging the positive effect of subjective norms, again, marketers could drive the sale of organic food.

Our study findings also show that consumer purchase intention closely relates to PBC, purchase attitude, and food therapy culture. Given this result, marketers should promote convenience sales and work to increase the availability of organic food, with the aim of reducing or removing resource constraints otherwise placed on consumers (e.g., Smith and Paladino 2010). Furthermore, as mentioned, marketers should cultivate consumers' positive attitudes toward the purchase of organic food by appealing to subjective norms and knowledge. More importantly, when developing marketing plans for organic food products, marketers are encouraged to consider food therapy culture as an essential motivating purchase factor, at least in the context of Chinese culture (Liu et al. 2015). By appealing to food therapy culture, marketers can emphasize among Chinese consumers the natural attributes of organic food, and hence encourage them to purchase organic food as part of a daily food therapy/healthcare regimen.

Finally, our study results demonstrate that purchase intention significantly mediates the relationships between each of purchase attitude, $\mathrm{PBC}$, and food therapy culture, and purchase decision; as such, they reveal that the consumer purchase decision tends to be driven by the aforementioned purchase factors via the mediating effect of purchase intention. Understanding this, marketers can help consumers make final purchase decision with regard to organic food by motivating their purchase intention in a variety of ways (i.e., by appealing to purchase attitude, $\mathrm{PBC}$, and food therapy culture).

\section{Study limitations and future directions}

While this study makes both theoretical and practical contributions to the literature, one should nonetheless consider its limitations. First, there is the matter of time constraints: We undertook data collection using the cross-sectional method, where data were collected in a specific period. This may give rise to sample bias, as no researcher can access more respondents within a significantly limited period. In the future, researchers could consider adopting a longitudinal method to ensure a representative sample and, to some extent, preclude sample bias.

Second, this study explores only those variables that affect consumer purchase attitude, from the perspectives of subjective norms, revealed information, and 
knowledge. There are many alternative variables that can be further explored with respect to consumer purchase attitude, while leveraging other theories or models. Moreover, the current conceptual framework does not extensively consider demographic data (e.g., gender, age, and education level). Accordingly, future research could incorporate demographic information as control variables and further explore their impacts on consumer purchase intention and purchase decision with respect to organic food.

\section{Screenshots of Amos outputs}

Screenshot 1: Model fit indices of model 1

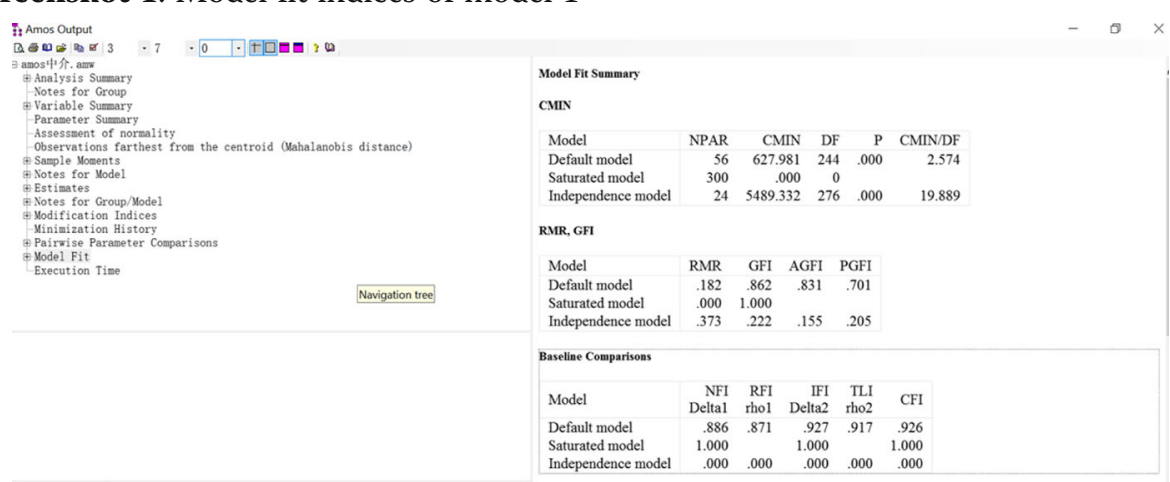

Screenshot 2: Model fit indices of model 2
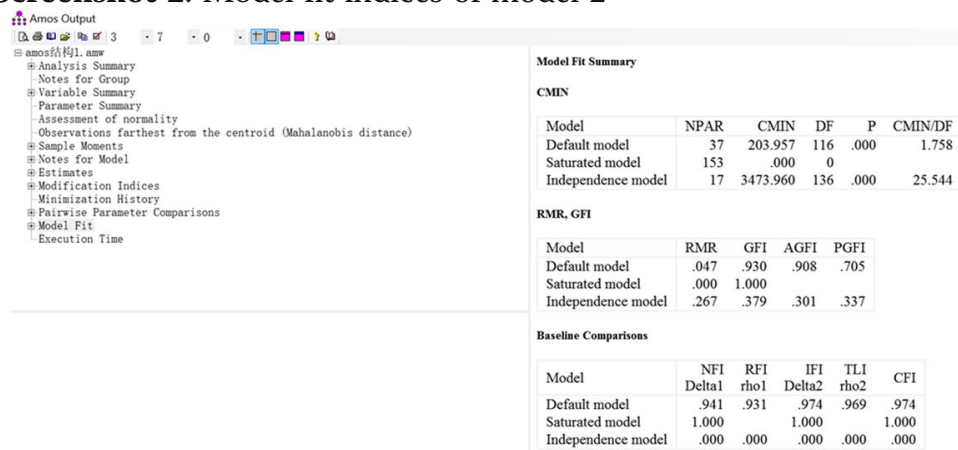

Screenshot 3: Standardized factor loading output of model 1
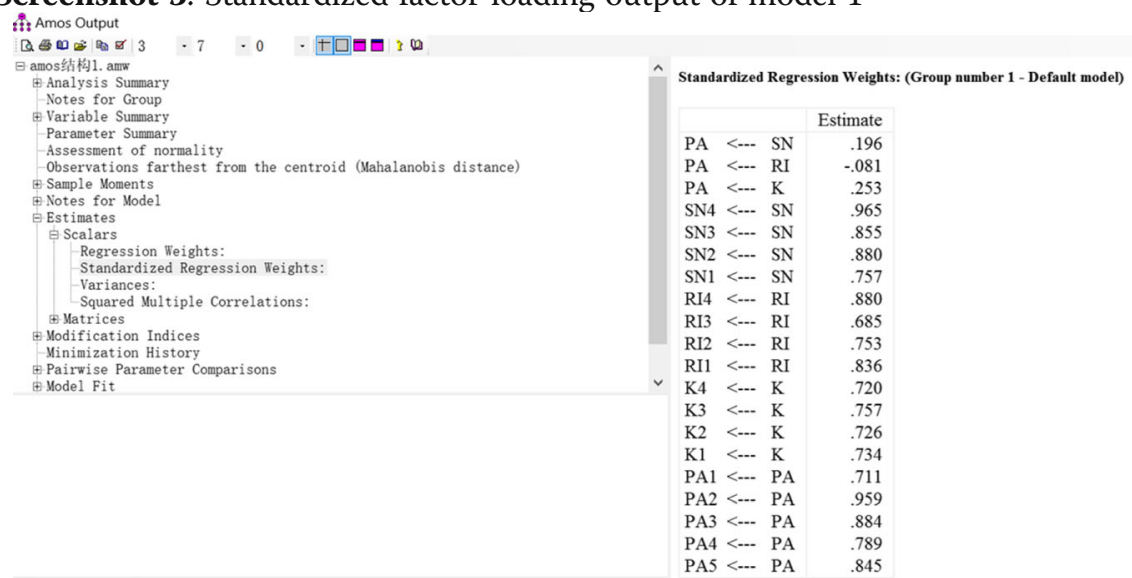

Screenshot 4: Standardized factor loading output of model 2 


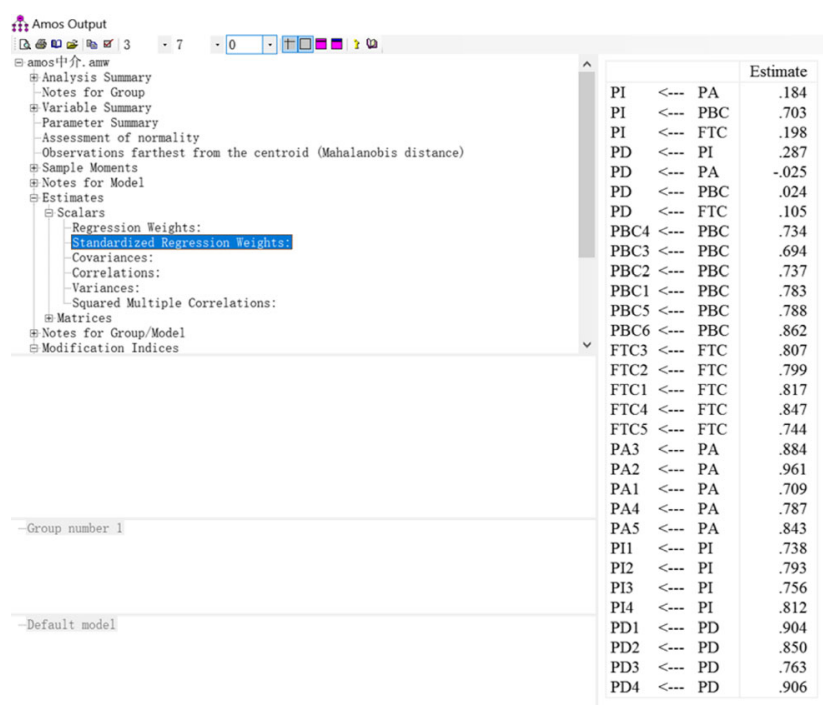

\section{Formulas for calculations}

Composite reliability $(\mathrm{CR})=\frac{\sum(\text { Standardized loading })^{2}}{\sum(\text { Standardized loading })^{2}+\sum(M E)}$

$$
\text { Measurement error }(\mathrm{ME})=1-(\text { Standardized loading })^{2}
$$

Average variance extracted $(\mathrm{AVE})=\frac{\sum(\text { Standardized loading })^{2}}{\text { Number of indicators }}$

\section{Abbreviations}

AGFI: Adjusted goodness of fit index; AVE: Average variance extracted; CFI: Comparative fit index; CR: Composite reliability; FTC: Food therapy culture; GFI: Goodness of fit index; KNWGE: Knowledge; NFI: Normed fit index;

PA: Purchase attitude; PBC: Perceived behavior control; PD: Purchase decision; Pl: Purchase intention; RI: Revealed information; RMSEA: Root mean square error of approximation; SN: Subject norms; TPB: Theory of planned behavior

\section{Acknowledgements}

We are appreciated to receive valuable comments given by the editor and two reviewers for helping us to correct and improve our manuscript.

\section{Authors' contributions}

NSJ conducted the conceptual framework design, questionnaire design and data analysis. SL conducted the write-up and data analysis. The authors approved the final manuscript for publication.

\section{Funding}

Not applicable.

\section{Availability of data and materials}

Please contact the authors for data requests. Correspondence should be addressed to Shimiao Li (E-mail: lishimiao@yahoo.com).

\section{Competing interests}

The authors declare that there are no competing interests.

Received: 21 April 2020 Accepted: 25 September 2020

Published online: 26 November 2020

\section{References}

Ajzen, I. (1985). From intentions to actions: A theory of planned behavior. In J. Kuhl, \& J. Beckmann (Eds.), Action control, (pp. 11-39). Berlin, Heidelberg: Springer.

Ajzen, I. (1991). The theory of planned behavior. Organizational Behavior and Human Decision Processes, 50(2), 179-211.

Alba, J. W., \& Hutchinson, J. W. (2000). Knowledge calibration: What consumers know and what they think they know. Journal of Consumer Research, 27(2), 123-156.

Al-Swidi, A., Mohammed Rafiul Huque, S., Haroon Hafeez, M., \& Noor Mohd Shariff, M. (2014). The role of subjective norms in theory of planned behavior in the context of organic food consumption. British Food Journal, 116(10), 1561-1580. 
Armitage, C. J., \& Conner, M. (2001). Efficacy of the theory of planned behaviour: A meta-analytic review. British Journal of Social Psychology, 40(4), 471-499.

Arvola, A., Vassallo, M., Dean, M., Lampila, P., Saba, A., Lähteenmäki, L., \& Shepherd, R. (2008). Predicting intentions to purchase organic food: The role of affective and moral attitudes in the theory of planned behaviour. Appetite, 50(2-3), 443-454.

Aslihan Nasir, V., \& Karakaya, F. (2014). Consumer segments in organic foods market. Journal of Consumer Marketing, 31(4), 263-277.

Basha, M. B., Mason, C., Shamsudin, M. F., Hussain, H. I., Salem, M. A., \& Ali, A. (2015). Consumer acceptance towards organic food. Global Journal of Interdisciplinary Social Sciences, 4(3), 29-32.

Bekele, G. E., Zhou, D., Kidane, A. A., \& Haimanot, A. B. (2017). Analysis of organic and green food production and consumption trends in China. American Journal of Theoretical and Applied Business, 3(4), 64-70.

Brouwer, A. M., \& Mosack, K. E. (2015). Expanding the theory of planned behavior to predict healthy eating behaviors: Exploring a healthy eater identity. Nutrition \& Food Science, 45(1), 39-53.

Brugarolas, M., Martinez-Carrasco, L., Bernabeu, R., \& Martinez-Poveda, A. (2010). A contingent valuation analysis to determine profitability of establishing local organic wine markets in Spain. Renewable Agriculture and Food Systems, 25(1), 35-44.

Cerri, J., Testa, F., \& Rizzi, F. (2018). The more I care, the less I will listen to you: How information, environmental concern and ethical production influence consumers' attitudes and the purchasing of sustainable products. Journal of Cleaner Production, 175, 343-353.

Chen, M. F. (2007). Consumer attitudes and purchase intentions in relation to organic foods in Taiwan: Moderating effects of food-related personality traits. Food Quality and Preference, 18(7), 1008-1021.

Chen, M. F., \& Tung, P. J. (2014). Developing an extended theory of planned behavior model to predict consumers' intention to visit green hotels. International Journal of Hospitality Management, 36, 221-230.

Cheng, S., Lam, T., \& Hsu, C. H. (2006). Negative word-of-mouth communication intention: An application of the theory of planned behavior. Journal of Hospitality \& Tourism Research, 30(1), 95-116.

Cranage, D. A., Conklin, M. T., \& Lambert, C. U. (2005). Effect of nutrition information in perceptions of food quality, consumption behavior and purchase intentions. Journal of Foodservice Business Research, 7(1), 43-61.

Dean, M., Raats, M. M., \& Shepherd, R. (2008). Moral concerns and consumer choice of fresh and processed organic foods. Journal of Applied Social Psychology, 38(8), 2088-2107.

Delafrooz, N., Paim, L. H., \& Khatibi, A. (2011). Understanding consumers internet purchase intention in Malaysia. African Journal of Business Management, 5(7), 2837-2846.

Deng, L., Wang, Y., Jin, C., Zhen, Z., \& Hu, D. P. (2012). Overview and research progress of traditional Chinese medicine dietary therapy in treating diabetes mellitus. Journal of Liaoning University of TCM, 14(10), 115-116.

Ellis, D., \& Thompson, F. M. (2018). The effect of wine knowledge type on variety seeking behavior in wine purchasing. Journal of Wine Research, 29(2), 71-86.

FiBL and IFOAM-Organics International. (2019). The World of Organic Agriculture Statistics and Emerging Trends 2019. https://shop.fibl.org/chen/mwdownloads/download/link/id/1202/.

Fiore, A. M., Jin, H. J., \& Kim, J. (2005). For fun and profit: Hedonic value from image interactivity and responses toward an online store. Psychology \& Marketing, 22(8), 669-694.

Fishbein, M., \& Ajzen, I. (1975). Belief, attitude, intention, and behavior: An introduction to theory and research. Reading: Addison-Wesley.

Fishbein, M., \& Ajzen, I. (2011). Predicting and changing behavior: The reasoned action approach. New York: Taylor \& Francis.

Fornell, C., \& Larcker, D. F. (1981). Evaluating structural equation models with unobservable variables and measurement error. Journal of Marketing Research, 18(1), 161-188.

Fowler, D. C., Yuan, J. J., Meng, F., \& Xu, Y. (2012). Tourism shopping behavior: Planned, impulsive, or experiential? International Journal of Culture, Tourism and Hospitality Research, 6(3), 250-265.

Gad Mohsen, M., \& Dacko, S. (2013). An extension of the benefit segmentation base for the consumption of organic foods: A time perspective. Journal of Marketing Management, 29(15-16), 1701-1728.

Gracia, A., \& de Magistris, T. (2008). The demand for organic foods in the south of Italy: A discrete choice model. Food Policy, 33(5), 386-396.

Guagnano, G. A., Stern, P. C., \& Dietz, T. (1995). Influences on attitude-behavior relationships: A natural experiment with curbside recycling. Environment and Behavior, 27(5), 699-718.

Han, H., Hsu, L. T. J., \& Sheu, C. (2010). Application of the theory of planned behavior to green hotel choice: Testing the effect of environmental friendly activities. Tourism Management, 31(3), 325-334.

Han, T. I., \& Stoel, L. (2016). The effect of social norms and product knowledge on purchase of organic cotton and fair-trade apparel. Journal of Global Fashion Marketing, 7(2), 89-102.

Hartmann, P., \& Apaolaza-lbáñez, V. (2012). Consumer attitude and purchase intention toward green energy brands: The roles of psychological benefits and environmental concern. Journal of Business Research, 65(9), 1254-1263.

Hasan, H. N., \& Suciarto, S. (2020). The influence of attitude, subjective norm and perceived behavioral control towards organic food purchase intention. Journal of Management and Business Environment, 1(2), 132-153.

Hsu, C. L., Chang, C. Y., \& Yansritakul, C. (2017). Exploring purchase intention of green skincare products using the theory of planned behavior: Testing the moderating effects of country of origin and price sensitivity. Journal of Retailing and Consumer Services, 34, 145-152

Irianto, H. (2015). Consumers' attitude and intention towards organic food purchase: An extension of theory of planned behavior in gender perspective. International Journal of Management, Economics and Social Sciences, 4(1), 17-31.

Jaiswal, D., \& Kant, R. (2018). Green purchasing behaviour: A conceptual framework and empirical investigation of Indian consumers. Journal of Retailing and Consumer Services, 41, 60-69.

Jin, B., \& Hye Kang, J. (2011). Purchase intention of Chinese consumers toward a US apparel brand: A test of a composite behavior intention model. Journal of Consumer Marketing, 28(3), 187-199.

Kim, E., Ham, S., Yang, I. S., \& Choi, J. G. (2013). The roles of attitude, subjective norm, and perceived behavioral control in the formation of consumers' behavioral intentions to read menu labels in the restaurant industry. International Journal of Hospitality Management, 35, 203-213. 
Kim, H., \& Bonn, M. A. (2015). The moderating effects of overall and organic wine knowledge on consumer behavioral intention. Scandinavian Journal of Hospitality and Tourism, 15(3), 295-310.

Kim, M., \& Lennon, S. (2008). The effects of visual and verbal information on attitudes and purchase intentions in internet shopping. Psychology \& Marketing, 25(2), 146-178.

Kim, M., \& Lennon, S. J. (2000). Television shopping for apparel in the United States: Effects of perceived amount of information on perceived risks and purchase intentions. Family and Consumer Sciences Research Journal, 28(3), 301-331.

Krejcie, R. V., \& Morgan, D. W. (1970). Determining sample size for research activities. Educational and Psychological Measurement, 30(3), 607-610.

Krueger Jr., N. F., Reilly, M. D., \& Carsrud, A. L. (2000). Competing models of entrepreneurial intentions. Journal of Business Venturing, 15(5-6), 411-432.

Kumar, A., \& Smith, S. (2018). Understanding local food consumers: Theory of planned behavior and segmentation approach. Journal of Food Products Marketing, 24(2), 196-215.

Lee, K. H., Bonn, M. A., \& Cho, M. (2015). Consumer motives for purchasing organic coffee: The moderating effects of ethical concern and price sensitivity. International Journal of Contemporary Hospitality Management, 27(6), 1157-1180.

Liang, R. D. (2016). Predicting intentions to purchase organic food: The moderating effects of organic food prices. British Food Journal, 118(1), 183-199.

Lim, Y. J., Osman, A., Salahuddin, S. N., Romle, A. R., \& Abdullah, S. (2016). Factors influencing online shopping behavior: The mediating role of purchase intention. Procedia Economics and Finance, 35(5), 401-410.

Lin, P. C., \& Huang, Y. H. (2012). The influence factors on choice behavior regarding green products based on the theory of consumption values. Journal of Cleaner Production, 22(1), 11-18.

Lin, T. M., Lu, K. Y., \& Wu, J. J. (2012). The effects of visual information in eWOM communication. Journal of Research in Interactive Marketing, 6(1), 7-26.

Liu, C., Cai, X., \& Zhu, H. (2015). Eating out ethically: An analysis of the influence of ethical food consumption in a vegetarian restaurant in Guangzhou, China. Geographical Review, 105(4), 551-565.

Liu, X., Wang, C., Shishime, T., \& Fujitsuka, T. (2012). Sustainable consumption: Green purchasing behaviours of urban residents in China. Sustainable Development, 20(4), 293-308.

Maichum, K., Parichatnon, S., \& Peng, K. C. (2016). Application of the extended theory of planned behavior model to investigate purchase intention of green products among Thai consumers. Sustainability, 8(10), 1-20.

McCarthy, B. L. (2015). Trends in organic and green food consumption in China: Opportunities and challenges for regional Australian exporters. Journal of Economic \& Social Policy, 17(1), 6-31.

McClure, C., \& Seock, Y. K. (2020). The role of involvement: Investigating the effect of brand's social media pages on consumer purchase intention. Journal of Retailing and Consumer Services, 53, 1-8.

Mitchell, V. W., \& Boustani, P. (1994). A preliminary investigation into pre- and post-purchase risk perception and reduction. European Journal of Marketing, 28(1), 56-71.

Nguyen, H. V., Nguyen, N., Nguyen, B. K., Lobo, A., \& Vu, P. A. (2019). Organic food purchases in an emerging market: The influence of consumers' personal factors and green marketing practices of food stores. International Journal of Environmental Research and Public Health, 16(6), 1-17.

Nitse, P. S., Parker, K. R., Krumwiede, D., \& Ottaway, T. (2004). The impact of color in the e-commerce marketing of fashions: An exploratory study. European Journal of Marketing, 38(7), 898-915.

Paul, J., Modi, A., \& Patel, J. (2016). Predicting green product consumption using theory of planned behavior and reasoned action. Journal of Retailing and Consumer Services, 29, 123-134.

Pham, Q., Tran, X., Misra, S., Maskeliūnas, R., \& Damaševičius, R. (2018). Relationship between convenience, perceived value, and repurchase intention in online shopping in Vietnam. Sustainability, 10(1), 142-156.

Phua, J., \& Kim, J. J. (2018). Starring in your own Snapchat advertisement: Influence of self-brand congruity, self-referencing and perceived humor on brand attitude and purchase intention of advertised brands. Telematics and Informatics, 35(5), 1524-1533.

Pisitsankkhakarn, R., \& Vassanadumrongdee, S. (2020). Enhancing purchase intention in circular economy: An empirical evidence of remanufactured automotive product in Thailand. Resources, Conservation and Recycling, 156, 1-11.

Ritter, A. M., Borchardt, M., Vaccaro, G. L., Pereira, G. M., \& Almeida, F. (2015). Motivations for promoting the consumption of green products in an emerging country: Exploring attitudes of Brazilian consumers. Journal of Cleaner Production, 106, $507-520$.

Rohman, F., Abadi, Y. B., Soelton, M., Prasetyo, N., \& Saratian, E. T. (2020). The effect of environmentally friendly paper toward purchasing intention. In 4th International Conference on Management, Economics and Business (ICMEB 2019), (pp. 120126). Paris: Atlantis Press.

Sahota, A. (2018). The global market for organic food and drink. In H. Willer, \& J. Lernoud (Eds.), The world of organic agriculture. Statistics and emerging trends 2018, (pp. 145-150). Bonn: Research Institute of Organic Agriculture (FiBL) and IFOAM-Organics international.

Scalco, A., Noventa, S., Sartori, R., \& Ceschi, A. (2017). Predicting organic food consumption: A meta-analytic structural equation model based on the theory of planned behavior. Appetite, 112, 235-248.

Schmalfuß, F., Mühl, K., \& Krems, J. F. (2017). Direct experience with battery electric vehicles (BEVs) matters when evaluating vehicle attributes, attitude and purchase intention. Transportation Research Part F: Traffic Psychology and Behaviour, 46, 47-69.

Sheppard, B. H., Hartwick, J., \& Warshaw, P. R. (1988). The theory of reasoned action: A meta-analysis of past research with recommendations for modifications and future research. Journal of Consumer Research, 15(3), 325-343.

Shin, Y. H., \& Hancer, M. (2016). The role of attitude, subjective norm, perceived behavioral control, and moral norm in the intention to purchase local food products. Journal of Foodservice Business Research, 19(4), 338-351.

Silayoi, P., \& Speece, M. (2004). Packaging and purchase decisions: An exploratory study on the impact of involvement level and time pressure. British Food Journal, 106(8), 607-628.

Singh, A., \& Verma, P. (2017). Factors influencing Indian consumers' actual buying behaviour towards organic food products. Journal of Cleaner Production, 167, 473-483.

Smith, S., \& Paladino, A. (2010). Eating clean and green? Investigating consumer motivations towards the purchase of organic food. Australasian Marketing Journal, 18(2), 93-104. 
Son, J., Jin, B., \& George, B. (2013). Consumers' purchase intention toward foreign brand goods. Management Decision, 51(2), 434-450.

Sreen, N., Purbey, S., \& Sadarangani, P. (2018). Impact of culture, behavior and gender on green purchase intention. Journal of Retailing and Consumer Services, 41, 177-189.

Stern, P. C., Dietz, T., Abel, T., Guagnano, G. A., \& Kalof, L. (1999). A value-belief-norm theory of support for social movements: The case of environmentalism. Human Ecology Review, 6(2), 81-97.

Sultan, P., Tarafder, T., Pearson, D., \& Henryks, J. (2020). Intention-behaviour gap and perceived behavioural control-behaviour gap in theory of planned behaviour: Moderating roles of communication, satisfaction and trust in organic food consumption. Food Quality and Preference, 81, 1-33.

Tariq, A., Wang, C., Tanveer, Y., Akram, U., \& Akram, Z. (2019). Organic food consumerism through social commerce in China. Asia Pacific Journal of Marketing and Logistics, 31(1), 202-222.

Tarkiainen, A., \& Sundqvist, S. (2005). Subjective norms, attitudes and intentions of Finnish consumers in buying organic food. British Food Journal, 107(11), 808-822.

Teng, C. C., \& Wang, Y. M. (2015). Decisional factors driving organic food consumption: Generation of consumer purchase intentions. British Food Journal, 117(3), 1066-1081.

Tung, S. J., Shih, C. C., Wei, S., \& Chen, Y. H. (2012). Attitudinal inconsistency toward organic food in relation to purchasing intention and behavior: An illustration of Taiwan consumers. British Food Journal, 114(7), 997-1015.

Ünal, S., Deveci, F. G., \& Yıldız, T. (2019). Do we know organic food consumers? The personal and social determinants of organic food consumption. Istanbul Business Research, 48(1), 1-35.

Vanhuele, M., \& Drèze, X. (2002). Measuring the price knowledge shoppers bring to the store. Journal of Marketing, 66(4), 72-85.

Westland, J. C. (2010). Lower bounds on sample size in structural equation modeling. Electronic Commerce Research and Applications, 9(6), 476-487.

Wu, H., \& Chen, J. (2017). Investigation of behavior of consumers of traditional Chinese medicine in Shenzhen. China Health Industry, 12, 14-16.

Xie, B., Wang, L., Yang, H., Wang, Y., \& Zhang, M. (2015). Consumer perceptions and attitudes of organic food products in eastern China. British Food Journal, 117(3), 1105-1121.

Xu, X., Hua, Y., Wang, S., \& Xu, G. (2020a). Determinants of consumer's intention to purchase authentic green furniture. Resources, Conservation and Recycling, 156, 1-8.

$\mathrm{Xu}, \mathrm{X}$., Wang, S., \& Yu, Y. (2020b). Consumer's intention to purchase green furniture: Do health consciousness and environmental awareness matter? Science of the Total Environment, 704, 1-44.

Xu, Z. X. (2003). The origin and application of diet therapy. Food Research and Development, 24, 18-19.

Yadav, R., \& Pathak, G. S. (2016). Intention to purchase organic food among young consumers: Evidence from a developing nation. Appetite, 96, 122-128.

Yao, J. F., Guo, Y., Dong, Y., Wang, F., \& Gao, J. (2012). Research progress of food therapy in traditional Chinese medicine. Nursing Journal of Chinese PLA, 29, 38-59.

Yao, Q. H., \& Wu, X. Z. (2019). Food therapy and health care: Provides the primary prevention strategy for people. Food Therapy and Health Care, 1(1), 1-1.

Żakowska-Biemans, S. (2011). Polish consumer food choices and beliefs about organic food. British Food Journal, 113(1), 122-137.

Zarei, G., Asgarnezhad Nuri, B., \& Noroozi, N. (2019). The effect of internet service quality on consumers' purchase behavior: The role of satisfaction, attitude, and purchase intention. Journal of Internet Commerce, 18(2), 197-220.

Zepeda, L., \& Deal, D. (2009). Organic and local food consumer behaviour: Alphabet theory. International Journal of Consumer Studies, 33(6), 697-705.

Zhou, Y., Thøgersen, J., Ruan, Y., \& Huang, G. (2013). The moderating role of human values in planned behavior: The case of Chinese consumers' intention to buy organic food. Journal of Consumer Marketing, 30(4), 335-344.

\section{Publisher's Note}

Springer Nature remains neutral with regard to jurisdictional claims in published maps and institutional affiliations.

\section{Submit your manuscript to a SpringerOpen ${ }^{\circ}$ journal and benefit from:}

- Convenient online submission

- Rigorous peer review

- Open access: articles freely available online

- High visibility within the field

- Retaining the copyright to your article

Submit your next manuscript at $\boldsymbol{s p r i n g e r o p e n . c o m ~}$ 